Article

\title{
Application of the Hierarchy Analysis Method to Assess Interchanges in Cracow
}

\author{
Katarzyna Solecka ${ }^{1}$ D , Lukasz Dumanowski ${ }^{1}$, Igor Taran ${ }^{2, *(D)}$ and Yana Litvinova ${ }^{2}$ (D) \\ 1 Faculty of Civil Engineering, Cracow University of Technology, Warszawska 24, 31-155 Krakow, Poland; \\ ksolecka@pk.edu.pl (K.S.); lukaszdumanowski@gmail.com (Ł.D.) \\ 2 Transportation Management Department, Dnipro University of Technology, Dmytra Yavornytskoho 19, \\ 49005 Dnipro, Ukraine; litvinovayana87@gmail.com \\ * Correspondence: taran7077@gmail.com; Tel.: +380-976673251
}

check for

updates

Citation: Solecka, K.; Dumanowski,

Ł.; Taran, I.; Litvinova, Y. Application

of the Hierarchy Analysis Method to

Assess Interchanges in Cracow.

Sustainability 2021, 13, 10593. https:/ / doi.org/10.3390/su131910593

Academic Editors:

Elżbieta Macioszek,

Margarida Coelho, Anna Granà and Raffaele Mauro

Received: 23 July 2021

Accepted: 21 September 2021

Published: 24 September 2021

Publisher's Note: MDPI stays neutral with regard to jurisdictional claims in published maps and institutional affiliations.

Copyright: (c) 2021 by the authors. Licensee MDPI, Basel, Switzerland. This article is an open access article distributed under the terms and conditions of the Creative Commons Attribution (CC BY) license (https:// creativecommons.org/licenses/by/ $4.0 /)$.

\begin{abstract}
We propose an assessment methodology of interchanges, which is based on one of four multi-criteria decision aid method, the AHP method, allowing the ranking of interchanges from best to worst with regard to specific criteria. The selected criteria account for different evaluation aspects (social, technical, functional, environmental, and economic ones). The final ranking of the interchanges from best to worst allows making conclusions related to assessed elements of interchanges, which should be improved to make interchanges friendlier to the passengers. The proposed interchange assessment method allows the identification of the weakest elements of the assessed interchanges, which require improvement in order to make the interchanges friendlier for passengers, with a view to increasing the number of passengers and boosting passengers' willingness to use the interchanges.
\end{abstract}

Keywords: interchanges; multiple criteria decision aid; AHP method

\section{Introduction}

The stable growth of urban population and the global tendency for urban sprawl have given rise to changes in mobility patterns [1]. The municipal transport as well as concurrent traffic and transport infrastructure, which should correspond to both interest and realia of time, are important for the progress of the current mega-cities. Using and combining the flexibly of different transport modes on a single trip is suggested [2] as being crucial to a more efficient and sustainable urban transport system. Alternatively, Monzon et al. [3] believe that the increase in multi-modal mega-city journeys makes public transport less attractive.

Despite certain improvements of design and performance processes of transportation systems of public transport in cities, travel patterns in urban areas are becoming increasingly complex, and many public transport users need to transfer between its different modes for their daily trips. The above-mentioned may restrict seriously the mobility of elderly people, visually handicapped people, and physically disabled people since public transport provide them with full involvement in social and economic life. Sun and Lau [4] applied a go-along interview to understand how older people interact with walking environments when approaching public transport in high-density cities. It has been proved that adaptation of transport system elements (inclusive of interchanges) to their needs is the key way to improve a trip of such passenger categories $[5,6]$.

Hence, precise design (development) of interchanges, redistributing passenger flows among different transport modes, has become urgent and more relevant than ever since interchange or transfers for passengers in large multi-modal public transport networks are more or less inevitable [7]. The problem is extremely important for the developed European countries as well as for developing FSU countries such as Ukraine [8] or Kazakhstan [9], 
where problems connected with scheduling and building of the modern interchanges are still at their initial development stage.

Passenger-friendly interchange is the key component of any modern transportation system. World experience in the construction of such facilities shows that it helps relieve pedestrian and car traffic by reducing the effort required to change a vehicle and reducing the time spent on the road. According to Hernández and co-workers [10], the quality of the service provided in an urban transport interchange has a direct influence on the daily experience of travelers. The cities offer different variants of the interchanges, but it is difficult to determine which option is the best. The above-mentioned can be explained by the following. Currently, there is no logically perfect method of comparative analysis of interchanges at a design stage that would help substantiate planning concepts of the interchange supporting the most efficient interplay of all the elements of the transport system.

In Poland, the Act on public collective transport of 16 December 2010 [11] defines the term "integrated interchange" as "a place providing for comfortable change of means of transportation, provided with the required passenger infrastructure, in particular: parking spaces, transportation stops, ticket sales outlets, information systems to study timetables, information on transportation lines, transportation system". A paper that considers interchanges should also mention Park and Ride interchanges [12,13], combining individual and collective transport types where passengers may leave their vehicles at special car parks located within the site of an interchange and continue traveling by means of collective transport. European countries have no standards or regulations specifying how interchanges should be developed, but good practices can be found in modern literature on this subject. The question is how to evaluate and compare the advantages and disadvantages caused by various interchanges.

Researchers apply various criteria as indices to evaluate interchange parameters. Use of the criteria is stipulated by optimization of the interchange structure and functions or by improvements of its qualitative and quantitative indices. Rather often the following is used as the criteria: distances between the interchange elements [14,15]; service quality and passenger satisfaction [1,2,14-17]; data accessibility information exhaustiveness [14,16,18,19]; time factor $[1,2,15,17,18,20-23]$; personal safety $[14,16,21]$; combination of the parameters or their interdependence $[16,17,23,24]$.

Bryniarska and Żakowska [14] proposed a comprehensive analysis (on the basis of the assessment of selected interchanges in Cracow, Poland) that takes into account the distance between tram/bus stops within the interchange; it considers the quality of the infrastructure maintenance of stops and footpath, availability and comprehensiveness of information for passengers and personal safety and the safety of the traffic as well as qualitative dimensions of these indicators. Lunke [15] defines the satisfaction of commuters with their last trip to work in Oslo (Norway). The findings indicate that efficient transport routes with short waiting times and reliable time use are more important than short distances to stations and direct routes. Chauhan et al. [16] examine the factors ('transfer environment and important facilities'; 'safety and security'; 'transport modes and travel information'; 'accessibility and signposting'; 'comfort, convenience, and quality of environment' and 'staff management and ticketing') and their effects influencing the service quality of MultiModal Transportation Hub in Anand Vihar, Delhi. While applying their own methods, Shesterov and Mikhailov [20] analyze the time cost of making interchanges at transit hubs in Saint Petersburg (the Russian Federation), based on the data obtained in systemic inspections between the 1980s and 2018.

Oostendorp and Gebhardt [2] analyze how intermodality is practiced in everyday mobility (for example, in different neighborhoods of Berlin) by examining the appropriate combinations of modes, travel goals, spatial differentiation, and user requirements. Four essential components of an urban public transport journey are evaluated by Espino and co-workers: access/egress walking time, waiting time, transfers between different legs of a trip, and security, both in- an out-of-vehicle [21]. The research results [1] highlight the ambivalent nature of the urban transport interchanges-the functional aspects identified 
contribute to facilitating the transfer and reducing the waiting time, and the psychological factors make the stay more comfortable for users.

To aid the designers of multi-modal transport interchanges, performance measures such as the average area occupied by commuters, blocking probability, average sojourn time, and throughput have been identified [22]. Mulley and Nelson [18] discuss the principles of network planning, including a discussion of timeframes and the necessity of understanding how network planning outcomes fit into the demand for a trip by the end user and the role of public transport in the future in the post-COVID-19 world. Gkiotsalitis [19] represents a model modifying the public transport service patterns to account for the imposed COVID-19 capacity. The model has been tested in a bus line connecting the University of Twente (The Netherlands) with its surrounding cities. Additionally, for the city of Amsterdam (The Netherlands), [24] proposes a multi-modal route choice and assignment model that allows users to combine line/schedule-based public transport systems and on-demand services or use them as individual modes. Lois et al. [17] analyze how attitudes towards several service factors can predict general satisfaction with the Moncloa transport interchange in Madrid, Spain. They also examine the relationship between waiting time and perceived quality. The authors prove that reducing transfer disruption in multi-modal trips is a key element for ensuring seamless mobility in big cities.

Yen et al. [7] analyze the interchange effects from an analysis of trip patterns of passengers in Southeast Queensland, Australia. Lee and co-workers [23] develop a transit assignment model, which takes account of the actual commute time, congestion, and fare of the public transport in a Hong Kong Island using a simulation model MATSim. The model of transport line synchronization in a transfer node, proposed by [25], is based on simulations of the demand for changing the public transport lines. In order to evaluate the objective function, simulations of public transport lines of Cracow city (Poland) servicing the passengers in a transfer node were provided. As it follows from the review, the time factor is one of the key parameters influencing the selection of a transport mode if only a passenger is satisfied by the transport mode accessibility as well as its service quality.

The subject of designing and assessment of interchanges is referred to in multiple EU projects (MIMIC, PIRATE, GUIDE, LINK, NICHES+, NODES, and CITY HUB). Examples of the most recent projects include NODES [26-28] and City-HUB projects [3]. NODES proposal is an R\&D project of the European Commission aiming to build a toolbox to support European cities in the design and operation of new or upgraded public transport interchanges. The underlying hypothesis is that the interchange could be a catalyst of life and security in the city. The City-HUB 7FP project1 has developed a three-year schedule for deploying new interchanges and improving existing ones. One dimension of integration is to reduce the disruption of transfer among modes and interchanges as the best solution when a large number of travelers has to transfer. Other interchanges related projects include HERMES [29] and Alliance [30].

In the literature, Polish interchanges are assessed with the indicator assessment method (AMPTI-Assessment Methodology for Public Transport Interchanges), developed in 2010 and published in the document "Analysis of the organization and functioning of interchanges in the capital city of Warsaw" [31]. Subsequently, the methodology was developed and presented in the document "Use of the indicator method and questionnaires to assess selected interchanges in Warsaw" [32]. The document contains 14 detailed quantitative indicators to assess interchanges. However, Olszewski and co-workers [31] recommend the use of eight indicators. The proposed indicators relate to the following aspects of the node: compactness of the node, legibility of the node, additional equipment, core infrastructure, accessibility for the disabled, personal safety, safety in motion, and passenger information. The objective of this article is to assess interchanges in Cracow on the basis of the indicators proposed in AMPTI, relying on a multiple criteria decision aid method. 


\section{Research Methodology}

In order to assess interchanges, one of the existing multiple criteria decision aid methods was used-the AHP method (analytic hierarchy process) [33]. Multiple criteria decision aid is a field of knowledge deriving from operational research - the method provides decision makers with tools and methods to support resolving complex multicriteria decision problems. A multiple criteria decision problem aid may cover [34,35]:

- The problem of choice (optimization) - the decision maker determines a subset of decisions (variants) considered the best ones in terms of the family of criteria in question. The most popular methods used to resolve problems of choice are the following: Electre Is and Electre I;

1. The problem of classification (sorting) - the decision maker splits a set of decisions (variants) into subsets (classes, categories) in accordance with the accepted standards. The methods applied to resolve problems of classification include, e.g., Electre TRI and UTADIS;

2. The problem of ranking - the decision maker aims to put the variants in order from the best to the worst. Among the most popular methods used to resolve problems of ranking are AHP (analytic hierarchy process), ANP (analytic network process), UTA (utility additive), SAW (simple additive weighting), Electre III/IV, Promethee, and Oreste.

One of the most popular multi-criteria ranking methods used in Poland [36-39] and in the world [40-44] is the AHP method, which is used in this study to evaluate the interchanges. The popularity of using this method, compared to other methods of multi-criteria decision support, is constantly growing [45]. It is widely used in many areas such as management, political science, sociology, transport, logistics, and economics. Here, only some of the examples of how the AHP method is applied for transport are considered. The method was used to evaluate the assumed variant solutions in terms of transport of oversize cargo [36], selection of routing schemes taking into environmental impact [37,43], multi-criteria evaluation of public transport projects [38], improvement of public transport [39,44], improvement of human security within railway stations [40], road accident factor prioritization [41], and building of a new metro station [42]. According to research by Huang et al. [45], out of 312 analyzed articles, 150 concern the AHP method, which is $48 \%$. This method, thanks to its simplicity, scientific basis, transparency of calculations, and the possibility of using qualitative assessments and free software, is a useful method and willingly used by researchers. The AHP method provides a multicriteria approach based on a compensation strategy of preference modeling and assuming the variants are comparable. The AHP method consists of four stages:

Stage 1: Development of a hierarchical model—determination of a hierarchy of factors (criteria) affecting problem solution (identification of the purpose of the decision process, variants and criteria). The hierarchical method is best presented using a hierarchical tree in order to facilitate the description of the decision structure of the problem. The hierarchical tree involves the following four levels:

Level 0 , identifying the objective of the decision process.

Level 1 , containing assessment criteria.

Level 2, containing assessment sub-criteria for each criterion.

Level 3, a specification of decision variants.

Stage 2: Assessment by way of comparing pairs-both of criteria and variants. Identification of the decision makers' local and global preferences. In stage II, at each hierarchy level, participants in the decision process specify their preferences in the form of relative importance assessments made for the pairs of decision criteria and variants. The comparable elements of the hierarchy (criteria, variants) are allocated points from 1 to 9 . The greater the priority that is given to an element, the higher its score. Intermediate values from 2 to 8 reflect the proportional extent of the relative advantage of one element over another. All the indicators are of compensatory nature - the value of assessment for a less important 
element (given less priority) in a pair is inverse to the value assigned to the most important element (given more priority). Therefore, values like $1 / 2,1 / 5$, or $1 / 7$ appear, and they are assigned to less desirable or less material elements. The indicator of relative materiality $a_{i j}$ between $K_{i}$ and $K_{j}$ criteria is presented with Formula (1):

$$
a_{i j}=\frac{e_{i}}{e_{j}}, i, j=1,2,3 \ldots n
$$

where $e_{i}$ is the criterion absolute $\operatorname{rank} K_{i}, e_{j}$ is the criterion absolute rank $K_{j}$, where $a_{i j} \in\{1$, $2,3 \ldots 9\}$.

Stage 3: Review of the cohesion of the matrix at all hierarchy levels or verification of the uniformity of the information on preferences specified by the decision maker. To this end, the consistency index $(C I)$ is calculated. The consistency index $(C I)$ is calculated from the following Formula (2) [33]:

$$
C I=\frac{\left(\lambda_{\max }-n\right)}{n-1},
$$

where $\lambda_{\max }$ is the maximum sum, calculated as the sum of the priority line; $n$ is the number of criteria.

Variants are fully consistent when $C I=0$. The priority line is the product of the sum in each column and the values of the priority vector in each line. In the end, the calculation is made of the consistency ratio $C R$ with Formula (3) [33]:

$$
C R=\frac{C I}{R I}
$$

where $R I$ is the Random Index, calculated in accordance with Table 1, determined by Saaty [33], where $n$ is the number of criteria.

Table 1. The values of RI subject to the number of criteria [33].

\begin{tabular}{ccccccccccc}
\hline $\boldsymbol{n}$ & $\mathbf{1}$ & $\mathbf{2}$ & $\mathbf{3}$ & $\mathbf{4}$ & $\mathbf{5}$ & $\mathbf{6}$ & $\mathbf{7}$ & $\mathbf{8}$ & $\mathbf{9}$ & $\mathbf{1 0}$ \\
\hline$R I$ & 0 & 0 & 0.52 & 0.89 & 1.11 & 1.25 & 1.35 & 1.40 & 1.45 & 1.49 \\
\hline
\end{tabular}

The limiting values of the consistency ratio $C R$ were defined by Saaty [33]. If the value of the $C R$ coefficient is less than or equal to 0.1 , it is assumed that the factor is accepted and the comparisons used are in agreement. Otherwise, when $C R>0.1$, it is recommended to repeat some or all of the comparisons in order to get rid of the pairwise incompatibility. This means that the information is inconsistent or an error was made (data input, calculations). In such situation, it is necessary to return to stage II of the AHP method algorithm. If the values of $C I$ and $C R$. at different levels of the hierarchy are equal to 0 , the preferences presented are perfectly consistent.

Stage 4: Final ranking of variants. In stage IV of the algorithm, the standardized absolute weights of variants and criteria obtained in stage II are aggregated with an additive usability function that synthesizes the weighted shares of elements from each level. The weights represent the share of the element in the global objective of the decision process. The algorithm of the AHP method results in a ranking of variants from top down, in compliance with the calculated values of their usability from the highest to the lowest. The individual steps of the method are presented in Figure 1 below. 

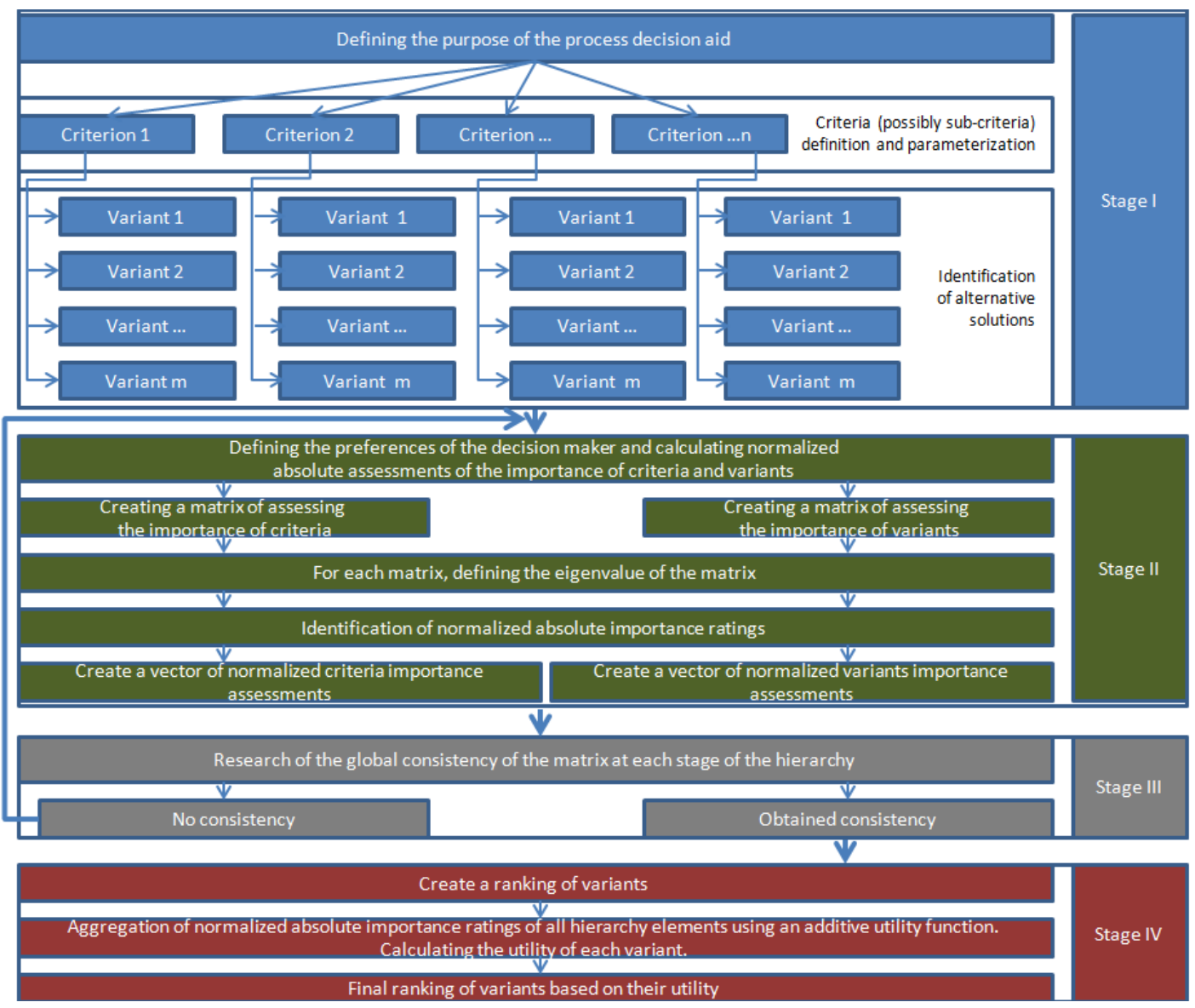

Figure 1. Methodological steps in AHP method.

However, the AHP method is subject to certain restrictions:

- The method does not allow in-comparability of criteria and variants with each other.

1. The AHP method is not flexible in terms of adding new variants. Each new variant added causes the destruction of the existing comparison matrices and the necessity to build new matrices.

2. This method relies on the knowledge and experience of the assessors because the method uses subjective expert opinions expressed in numbers.

3. When the number of criteria, sub-criteria and variants increases, the number of levels and elements of the hierarchy also increases, which makes the number of pairwise comparisons by the decision maker also larger, which increases the labor intensity and thus reduces the attractiveness of the method. The size of the comparison matrix with several dozen decision variants is very large.

4. During modeling and computational experiments, the values of the criteria are not used, which increases the risk of making a mistake while transforming the data.

\section{Application of the AHP Method to Assess Interchanges in Cracow}

In Cracow, there are about 18 interchanges of major importance for passengers of collective transport-those that are used by the largest number of passengers in a day (over 1200 passengers/day). The largest number of passengers was recorded at five interchanges with streams of over 14,000 a day on a regular working day [15]. For the multi-criteria analysis, the following interchanges were used as assessment variants: Variant 1 (W1)—Rondo Mogilskie (31.594 passengers/day); Variant 2 (W2)—Main Railway Station (47.537 passengers/day); Variant 3 (W3)—Krowodrza Górka Station (16.996 passengers/day); Variant 4 (W4)-ICE Congress Centre (18.186 passengers/day); Variant 5 (W5)—Rondo Grzegórzeckie (14.808 passengers/day). The locations of the interchanges 
are presented in Figure 2. Example of an analysis of the interchange in terms of traffic organization in Figures 3-10.

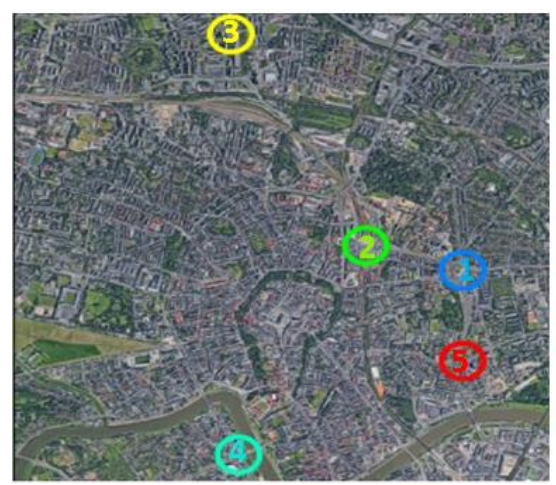

\section{(1) Rondo Mogilskie \\ 2) Dworzec Główny \\ Krowodrza Górka}

(4) Centrum Kongresowe ICE

(5) Rondo Grzegórzeckie

Figure 2. Locations of the interchanges used for the analysis. Source: Own elaboration with the use of Google Maps base.
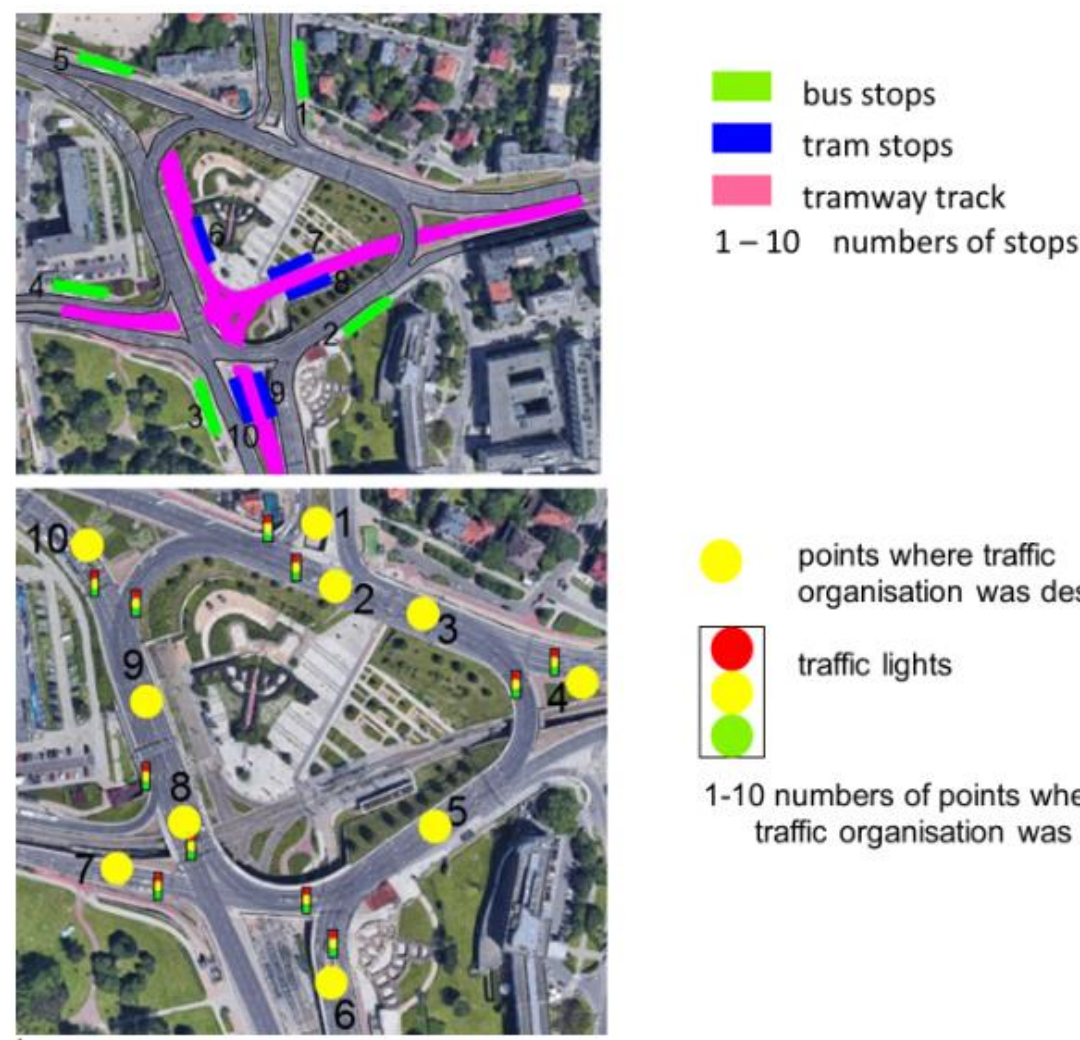

points where traffic organisation was described

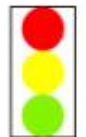

traffic lights

\section{1-10 numbers of points where traffic organisation was described}
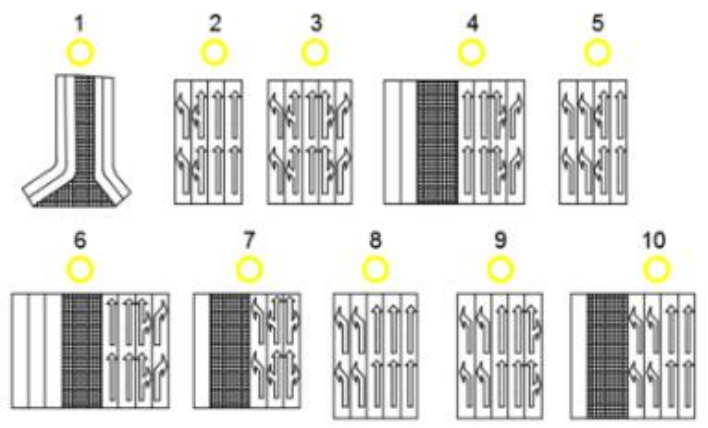

Figure 3. Example of an analysis of the Rondo Mogilskie interchange in terms of traffic organization. Source: Own elaboration with the use of Google Maps base. 


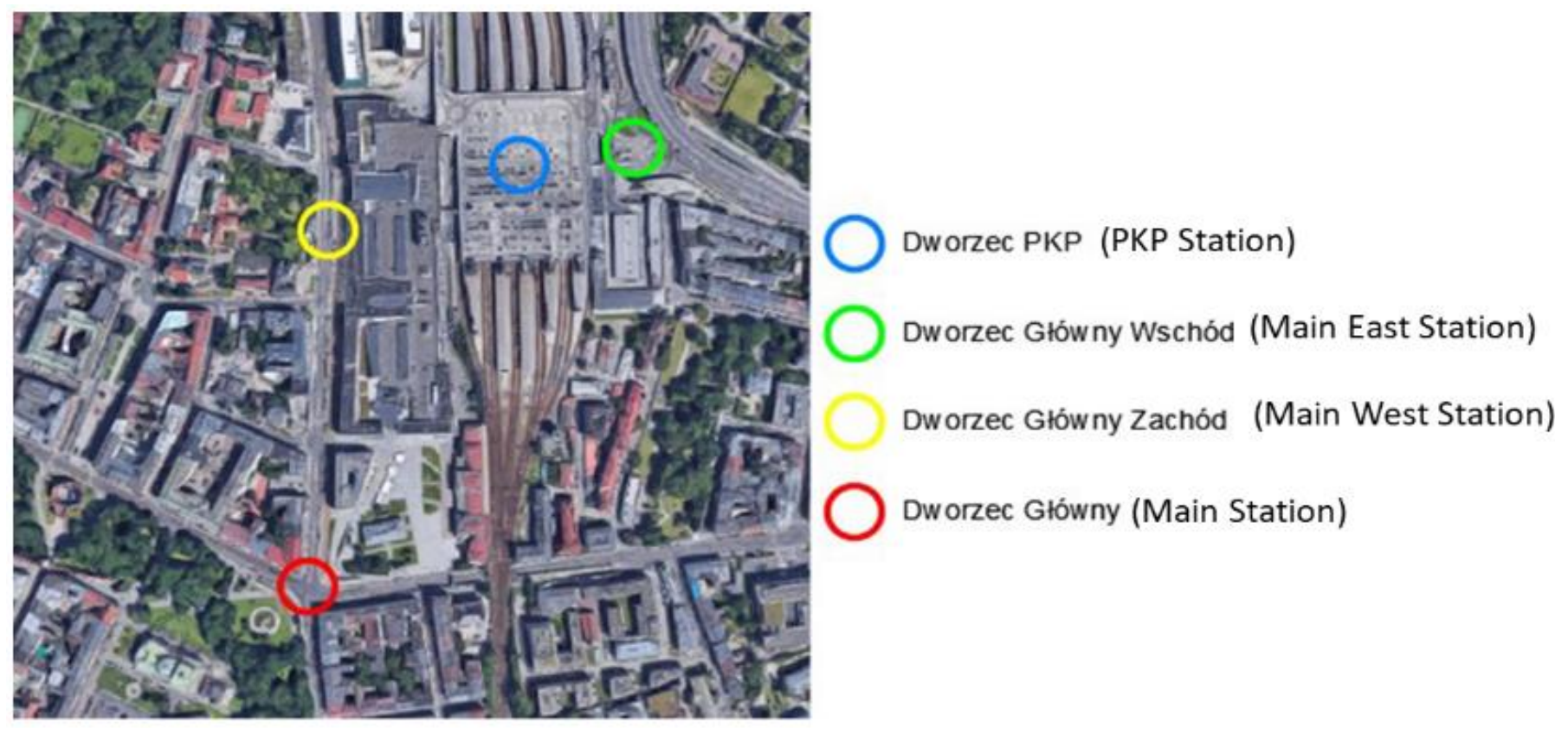

Figure 4. Diagram of the Main Railway Station interchange. Source: Own elaboration with the use of Google Maps base.
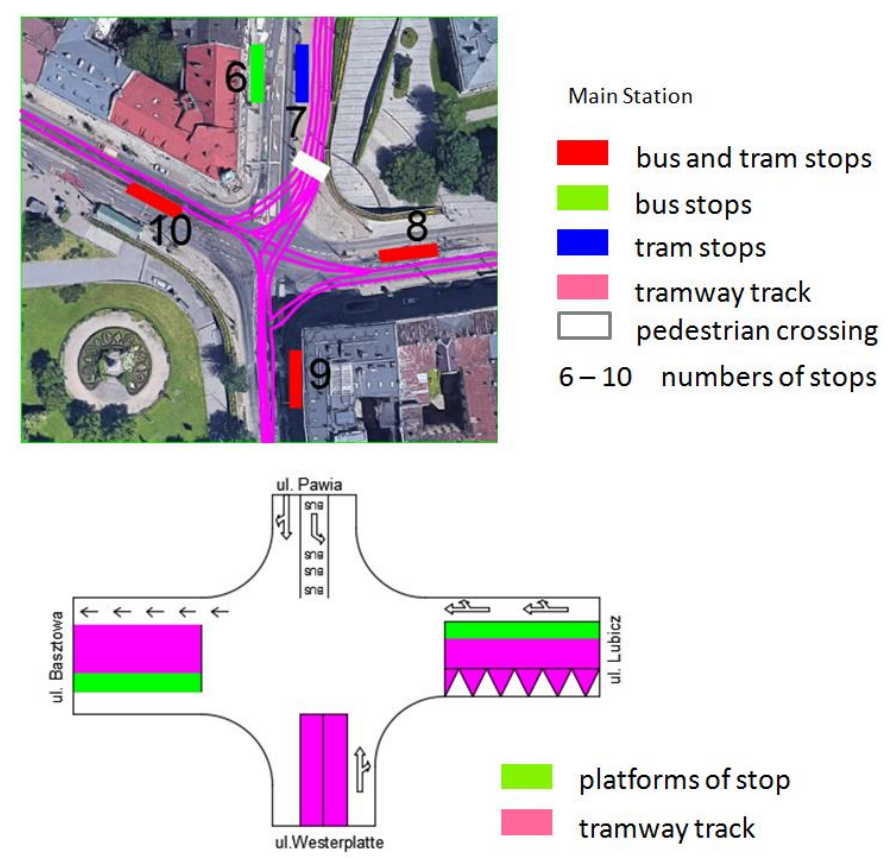

Figure 5. Example of an analysis of the bus and tram stop location on the Main Station and traffic organization. Source: Own elaboration with the use of Google Maps base. 


\section{Main Station Tunnel}

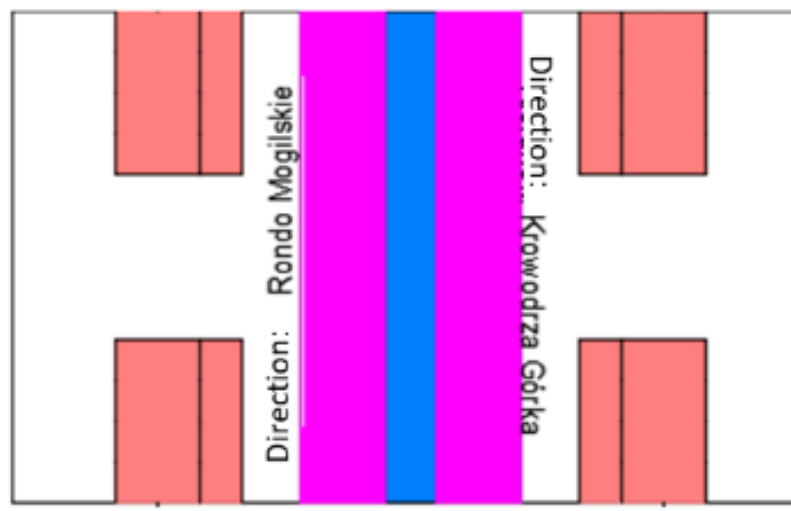

tramway track

ramps

Figure 6. Example of an analysis of the Main Station tunnel in terms of traffic organization. Source: Own elaboration.

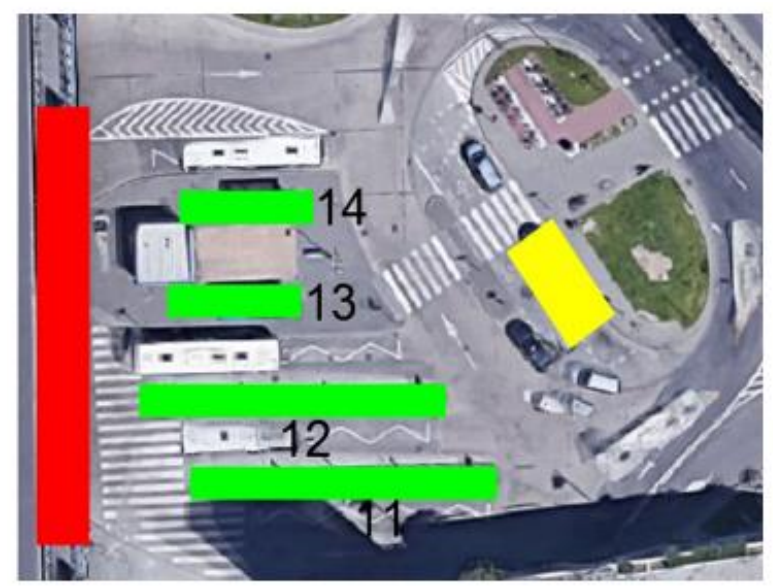

Main East Station

bus stops

ticket sales point

Kiss\&Ride parking

11-14 numbers of stops

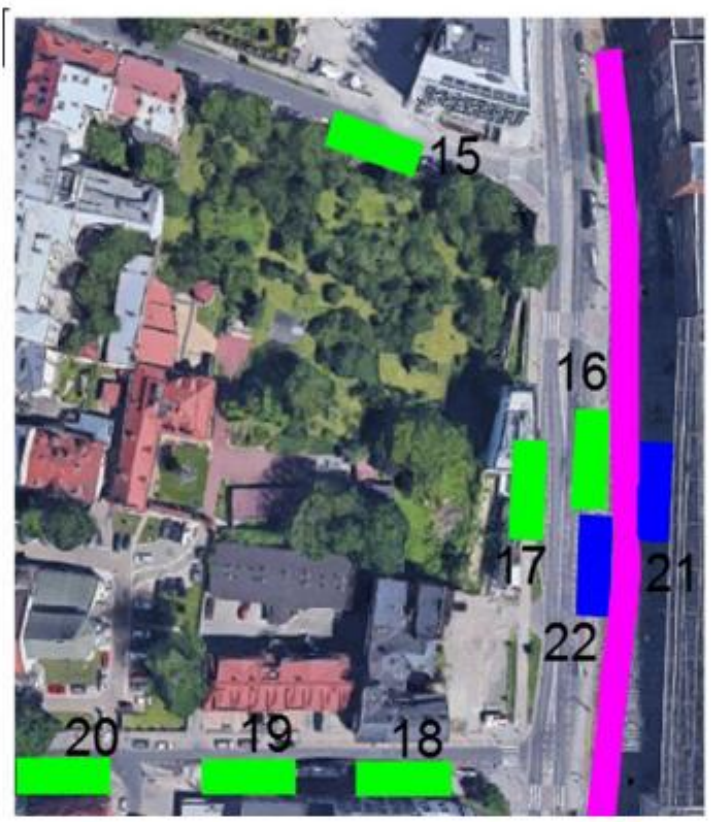

Main West Station

bus stops

tram stops

tramway track

$15-22$ numbers of stops

Figure 7. Example of an analysis of the bus and tram stops location on Main East and West Station. Source: Own elaboration with the use of Google Maps base. 


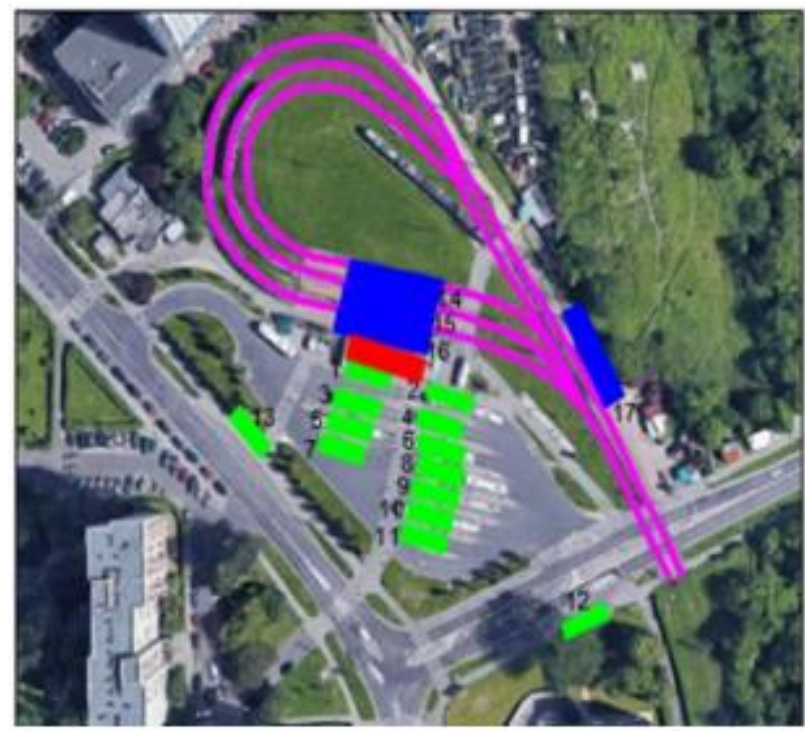

\section{bus stops}

tram stops

tramway track

ticket sales point

\section{1-17 numbers of stops}

Figure 8. Example of an analysis of the bus and tram stops location on Krowodrza Górka. Source: Own elaboration with the use of Google Maps base.
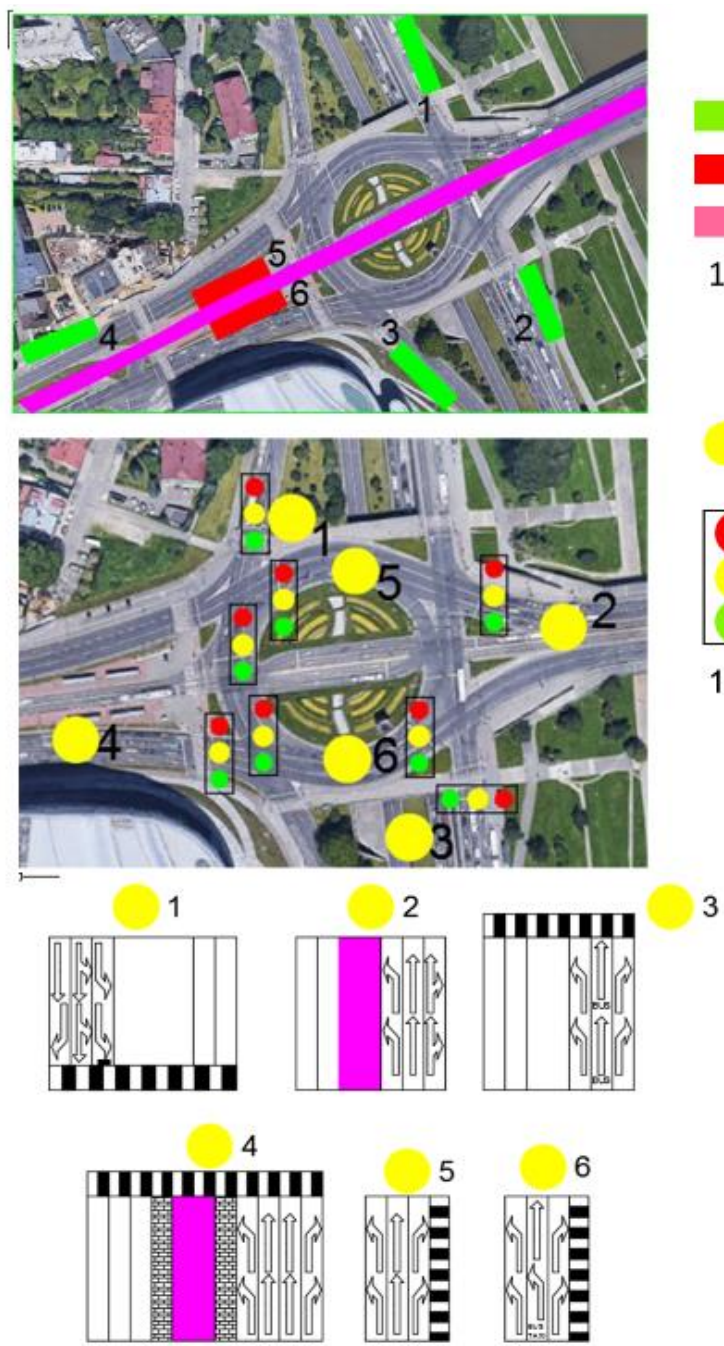

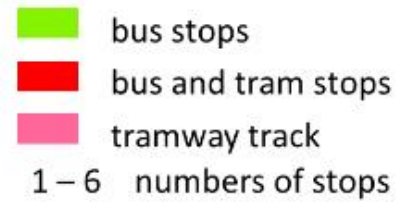

points where traffic organisation was described

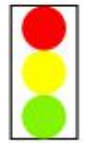

traffic lights

1-6 numbers of points where traffic organisation was described

tramway track

Figure 9. Example of an analysis of the Centrum Kongresowe ICE interchange in terms of traffic organization. Source: Own elaboration with the use of Google Maps base. 


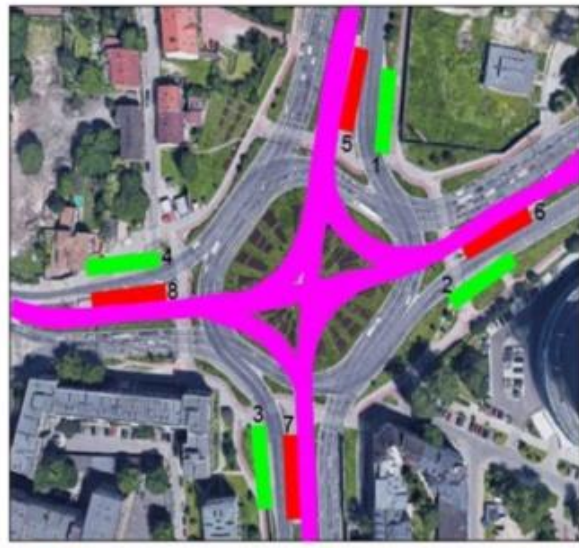

\section{bus stops}

bus and tram stops

tramway track

1-8 numbers of stops

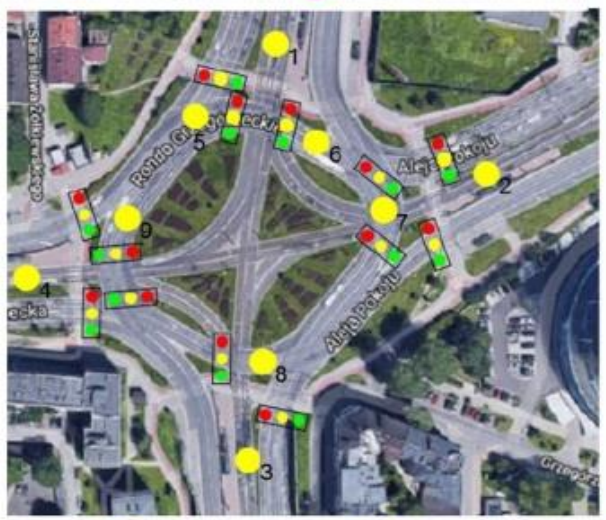

points where traffic organisation was described

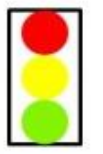

traffic lights

1-9 numbers of points where traffic organisation was described

1

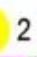 \\ 2}
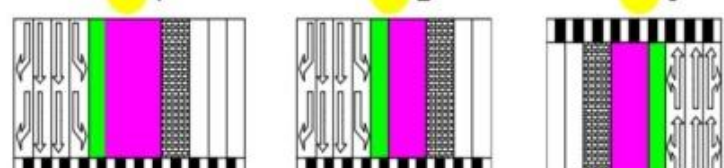

\section{IIIIIIIII}
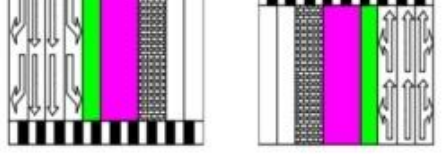

tramway track

greenery

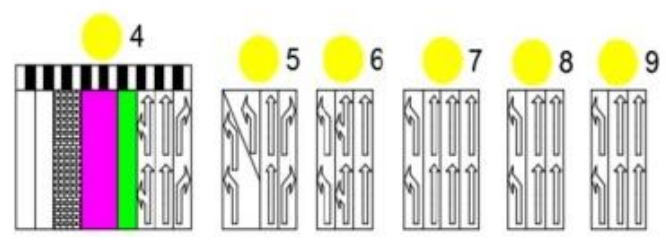

Figure 10. Example of an analysis of the Rondo Grzegórzeckie interchange in terms of traffic organization. Source: Own elaboration with the use of Google Maps base.

Each interchange was characterized in detail in terms of [15] interchange location, traffic organization in the interchange both for individual and collective transport vehicles (interchange chart-location of collective transport stops, pedestrian crossings, traffic lights, lanes for individual and collective transport traffic, common stops), number of bus and tram lines, frequency of operation in peak hours and outside of peak hours, types of stops, additional devices: ticket vending machines, kiosks, toilets, information points, information at stops (type of information), network of cycling paths in the interchange and within $500 \mathrm{~m}$ from the interchange (including the length of contraflow lanes, separated cycling paths), bicycle stands, condition of surface within the interchange, facilities for the handicapped (lifts, escalators, ramps), and parking.

A set of eight criteria were applied to assess interchanges. Definitions of the criteria were applied in compliance with the AMPTI methodology [31]:

- K1 Spatial compactness of the interchange-spatial compactness of the interchange consists of three indicators: average weighted time of walk between stops, average 
weighted length of a walk between stops, and average arithmetic mean of a walk between all platforms in the interchange.

1. K2 Interchange legibility - the indicator relies on the assumption that orientation in the interchange is facilitated with mutual visibility of stops: check of the number of stop posts, visible from each platform — or one-level interchanges; for multi-level interchanges, marked entrances to station buildings or tunnels are used instead of stop posts.

2. K3 Additional equipment-additional equipment at an interchange shall include roofing over platforms and pedestrian passages, benches, waste baskets, ticket vending machines, shops, toilets, taxi ranks, car parking, and bicycle stands, calculated as a percentage of all equipment at the interchange.

3. K4 Core infrastructure-the following criteria are taken into account in assessing the indicator: platform or pavement width, length of the platform, surface quality, no obstacles within stops, maximum curb height, and open-sided shelters. In order to accept the indicator as positive, all the criteria have to be complied with. The values of the indicator are calculated as percentage of platforms that meet the requirements concerning infrastructure quality; percentage of passage segments that meet the requirements concerning infrastructure quality.

4. K5 Accessibility for the handicapped and elderly-here, the following accessibility criteria have to be met: ramps and lifts by the stairs, handrails along the ramps, warning pavement slabs, well-marked edges along the platforms, lower curbs at road crossings, and sound signals at crossings with traffic lights. The values of the indicator are calculated as percentage of platforms that meet the criterion and percentage of passage segments that meet the criterion.

5. K6 Personal safety-the core criteria ensuring safety are good lighting and visual monitoring of interchange elements. The indicator is calculated as percentage of platforms that meet the criterion and percentage of passage segments that meet the criterion.

6. K7 Safety in motion - the indicator relates solely to pedestrian road crossings. The safety level is assessed by the type of crossing: underground passage or footbridge $=100 \%$; passage with traffic lights without collision with turning vehicles $=70 \%$; passage with traffic lights with collision with turning vehicles $=50 \%$; passage without traffic lights, zebra crossing $=30 \%$; unmarked passage $=0 \%$.

The indicator is calculated as an average safety level for all the road crossings within the interchange.

- K8 Passenger information-passenger information is required in complex interchanges so that they can function better. The core requirements are as follows: timetables and tariff information at stops, maps of an interchange and its surroundings, and network charts, including directional signs at platforms and branching of pedestrian passages. It is calculated as follows: percentage of platforms and pedestrian passages provided with information for passengers. Table 2 presents the obtained criteria values (K1-K8) for each interchange (variant). 
Table 2. Criteria value.

\begin{tabular}{ccccccc}
\hline \multicolumn{2}{c}{ Criteria } & \multicolumn{5}{c}{ Variants } \\
\hline $\begin{array}{c}\text { Direction of } \\
\text { Preferences/Units }\end{array}$ & V1 & V2 & V3 & V4 & V5 \\
\hline K1 & $\min [-]$ & 180.02 & 191.94 & 91.14 & 109.19 & 106.23 \\
\hline K2 & $\operatorname{max~[\% ]~}$ & 54 & 60 & 78 & 80 & 100 \\
\hline K3 & $\max [\%]$ & 66 & 60 & 49 & 48 & 49 \\
\hline K4 & $\max [\%]$ & 98 & 95 & 93 & 96 & 100 \\
\hline K5 & $\max [\%]$ & 68 & 63 & 46 & 60 & 81 \\
\hline K6 & $\max [\%]$ & 60 & 66 & 64 & 50 & 52 \\
\hline K7 & $\max [\%]$ & 79 & 31 & 19 & 64 & 60 \\
\hline K8 & $\max [\%]$ & 45 & 43 & 30 & 33 & 50 \\
\hline
\end{tabular}

Another step was to carry out a multi-criteria assessment of interchanges and to rank them from the top down with respect to the reviewed criteria category. The assessment was made with a variant ranking method-AHP. As a result of calculation experiments, the following results were obtained:

- Comparison matrix with criteria pairs where criteria were compared in pairs in compliance with the AHP method, applying scores from 1 to 7 and resulting in relative importance indicators. The values presented in Table 3 in the form of integers mean advantage of a criterion on the left-hand side over a criterion located on the right-hand side. Fractional values mean advantage of a criterion on the right-hand side over a criterion located on the left-hand side.

- Weights of individual criteria-Table 3 and the value of the inconsistency index. The highest weight was assigned to criterion K4-Core infrastructure- 0.341 and the lowest to criterion $\mathrm{K} 3$-additional equipment- 0.026 . The value of the consistency index $C I=0.014$. Consistency ratio $C R=0.01$. The ratio was under 0.1 , which means the assessments are consistent.

- Comparison matrix of variants with respect to individual criteria. To this end, important indicators were identified for the variants compared in pairs for each criterion. An example of variant assessment with respect to criterion K1 (spatial compactness of the interchange) is presented in Table 4.

Table 3. Comparison matrix of criteria pairs and criteria weights.

\begin{tabular}{cccccccccc}
\hline Criteria & K1 & K2 & K3 & K4 & K5 & K6 & K7 & K8 & Weight \\
\hline K1 & 1 & 1 & 3 & $1 / 7$ & $1 / 2$ & $1 / 3$ & $1 / 3$ & $1 / 5$ & 0.047 \\
K2 & 1 & 1 & 2 & $1 / 7$ & $1 / 2$ & $1 / 3$ & $1 / 3$ & $1 / 5$ & 0.044 \\
K3 & $1 / 3$ & $1 / 2$ & 1 & $1 / 9$ & $1 / 3$ & $1 / 5$ & $1 / 5$ & $1 / 7$ & 0.026 \\
K4 & 7 & 7 & 9 & 1 & 5 & 3 & 3 & 2 & 0.341 \\
K5 & 2 & 2 & 3 & $1 / 5$ & 1 & $1 / 2$ & $1 / 2$ & $1 / 3$ & 0.074 \\
K6 & 3 & 3 & 5 & $1 / 3$ & 2 & 1 & 1 & $1 / 2$ \\
K7 & 3 & 3 & 5 & $1 / 3$ & 2 & 1 & 1 & $1 / 2$ & 0.126 \\
K8 & 5 & 5 & 7 & $1 / 2$ & 3 & 2 & 2 & 1 & 0.126 \\
Total & 22.333 & 22.5 & 35 & 2.763 & 14.333 & 8.367 & 8.367 & 4.876 & 1 \\
Priority & 1.050 & 0.986 & 0.895 & 0.944 & 1.060 & 1.056 & 1.056 & 1.051 & 8.099 \\
\hline
\end{tabular}


Table 4. Comparison matrix by variant pairs with respect to the criterion K1.

\begin{tabular}{ccccccc}
\hline Variants & V1 & V2 & V3 & V4 & V5 & Weight \\
\hline V1 & 1 & 2 & $1 / 4$ & $1 / 4$ & $1 / 4$ & 0.0806 \\
V2 & $1 / 2$ & 1 & $1 / 5$ & $1 / 4$ & $1 / 4$ & 0.0576 \\
V3 & 4 & 5 & 1 & 2 & 2 & 0.3824 \\
V4 & 4 & 4 & $1 / 2$ & 1 & 1 & 0.2397 \\
V5 & 4 & 4 & $1 / 2$ & 1 & 1 & 0.2397 \\
\hline
\end{tabular}

With respect to criterion K1, the best was variant V3-Krowodrza Górka with a weight of 0.3824 . In terms of the reviewed criterion, $\mathrm{K} 1$ proved to be variant V2-Main railway Station with a weight of 0.0576 .

- Consistency index and consistency ratios. At each level of comparison of pairs of variants versus the criteria, the consistency index and consistency ratio were determined, which is presented in Table 5. This is an example of a specific matrix for pairwise comparisons according to the $\mathrm{K} 1$ criterion-which option showed the best result and which one the worst. Such matrices are created for each criterion (from K1 to K8). Subsequently, we get the validity of the option in relation to the considered criterion. The results are then used to select the best alternative.

Table 5. Consistency of assessment.

\begin{tabular}{lcccc}
\hline & Consistency Index CI & Random Index & Consistency Ratio CR & $\begin{array}{c}\text { Consistency of } \\
\text { Assessment }\end{array}$ \\
\hline Average distance of walk & 0.026 & 1.11 & 0.024 & yes \\
Legibility in interchange & 0.012 & 1.11 & 0.011 & yes \\
Additional equipment & 0.002 & 1.11 & 0.002 & yes \\
Core infrastructure & 0.019 & 1.11 & 0.017 & yes \\
Accessibility for the & 0.027 & 1.11 & 0.024 & yes \\
handicapped and elderly & 0.011 & 1.11 & 0.010 & yes \\
Personal safety & 0.007 & 1.11 & 0.006 & yes \\
Safety in motion & 0.013 & 1.11 & 0.012 & yes \\
Passenger information & & & & \\
\hline
\end{tabular}

As a result of the calculation of $C I$ and $C R$, it was determined that the provided information was consistent at each stage of the calculations.

- Final ranking. The last stage of the AHP method was to rank variants from top down on the basis of the calculated global usability of all variants (calculation of the usability function and its standardization), calculating the product of the weight for the criterion and the weight of the corresponding variant (usability of the variant for each criterion)-Tables 6 and 7.

As a result of a multi-criteria analysis using the AHP method, a final ranking of the variants was obtained; as a result, the best variant versus the reviewed criteria provided to be variant V5-Rondo Grzegórzeckie with a global assessment value of 28.22\%, while the worst variant proved to be variant V3-Krowodrza Górka with a global assessment of $14.08 \%$. The difference between the best and the worst variants is 14.14 percentage points, while the difference between the best-Rondo Grzegórzeckie and the second-ranked Rondo Mogilskie is 4.15 percentage points. 
Table 6. Usability of variants versus the criteria.

\begin{tabular}{lccccc}
\hline \multirow{1}{*}{ Criteria } & \multicolumn{3}{c}{ Variants } & V4 & V5 \\
\cline { 2 - 6 } & $\mathbf{V 1}$ & $\mathbf{V 2}$ & $\mathbf{V 3}$ & 0.0113 & 0.0113 \\
Average distance of walk & 0.0038 & 0.0027 & 0.0180 & 0.0099 & 0.0175 \\
Legibility in interchange & 0.003 & 0.0045 & 0.0090 & 0.0032 & 0.0032 \\
Additional equipment & 0.0101 & 0.0060 & 0.0032 & 0.0574 & 0.0997 \\
Core infrastructure & 0.0771 & 0.0574 & 0.0499 & 0.0110 & 0.0277 \\
Accessibility for the & 0.0182 & 0.0120 & 0.0050 & 0.0127 & 0.0138 \\
handicapped and elderly & 0.0262 & 0.0407 & 0.0328 & 0.0313 & 0.0285 \\
Personal safety & 0.0522 & 0.0093 & 0.049 & 0.0209 & 0.0807 \\
Safety in motion & 0.0501 & 0.0460 & 0.0180 & 0.1577 & 0.2822 \\
Passenger information & 0.2407 & 0.1786 & 0.1408 & & \\
Weighted sum & & & &
\end{tabular}

Table 7. Final ranking.

\begin{tabular}{cccc}
\hline $\begin{array}{c}\text { Position in the } \\
\text { Ranking }\end{array}$ & Variant & $\begin{array}{c}\text { Name of the } \\
\text { Interchange }\end{array}$ & Global Score \\
\hline 1 & V5 & Rondo Grzegórzeckie & $28.22 \%$ \\
2 & V1 & Rondo Mogilskie & $24.07 \%$ \\
3 & V2 & Main Railway Station & $17.86 \%$ \\
4 & V4 & ICE Congress Centre & $15.77 \%$ \\
5 & V3 & Krowodrza Górka & $14.08 \%$ \\
\hline
\end{tabular}

\section{Discussion}

This article discusses the assessment of interchange nodes using one of the multicriteria decision support methods, namely, the AHP method, along with a set of criteria proposed under the AMPTI method [31]. The assessment carried out in this way allows for a comprehensive analysis of various criteria related to spatial compactness of the interchange, legibility interchange, infrastructure quality, the necessary equipment facilitating passengers to move around the interchange, including people with reduced mobility, personal safety, and traffic safety, and criteria related to information about passengers. The assessment carried out in this way also makes it possible to identify the interchange elements that need to be improved and which aspects of the infrastructure and elements related to interchange movement should be given special attention. Such information may prove useful when planning new and modernizing existing interchanges. We used the method to assess interchanges in Cracow, Poland, and the results in the form of the final ranking of the interchanges under consideration show that the Rondo Grzegórzeckie interchange is the best solution in terms of the criteria under consideration, obtaining a global rating of $28.22 \%$. The Rondo Mogilskie interchange was the second in the ranking with a global rating of $24.07 \%$. The high position of these variants in the ranking resulted mainly from the obtained high utility values of the variants in relation to the following criteria: core infrastructure, passenger information, personal safety, and safety in motion, which were characterized by high weights. The winning W5 variant was characterized by the highest utility value of the variants in relation to the core infrastructure and passenger information criterion, obtaining utility values of 0.0997 and 0.0807 , respectively. Although the final result of the study is the interchanges ranking, the individual stages of the analysis also provide important information such as the significance of a specific element of interchange equipment in relation to the studied group of users (weighting of the assessment criteria), and the extent to which the analyzed interchanges meet the requirements with regard to the considered elements of interchange equipment (the utility of the variant in relation to the given criterion). In addition, this type of analysis also provides information about the strengths and weaknesses of the analyzed interchange nodes, making it easier to identify elements that require improvement. With regard to the importance of the criteria, as a 
result of the analyses, the most important criteria turned out to be K4-basic infrastructure, K6-personal safety, K7-safety in motion, and K8-passenger information. The utility values of a given variant (the interchange) in relation to the considered criteria show which criteria should be improved in order to make the variant more passenger-friendly. The attractiveness of the interchange is evidenced by the high utility values of the variants in relation to a given criterion. The higher the utility of a variant, the more user-friendly and attractive the variant is. For example, the highest utility value of the variant in relation to one of the most important criteria for passengers-the passenger information criterionwas obtained by the W5-Rondo Grzegórzeckie variant with a result of 0.0807 , while the lowest utility values in relation to this criterion were obtained by variants $\mathrm{W} 3$ and W4, which means that in the case of interchanges W3-Main Railway Station and W4-ICE Congress Center focus primarily on improving elements related to passenger information.

The results are largely consistent with findings of previous studies, including Starzyńska et al. [46] and the results of the City-HUB project $[29,47,48]$. The above research shows that the most important elements that people traveling by public transport pay attention to are primarily elements related to the quality of the stop infrastructure (e.g., height and width of the stop platform, platform roof, height of the vehicle floor), information quality (legibility of information, height at which information is located, ease of reception, voice information informing about approaching vehicles, clear timetables), according to the study by Starzyńska et al. [46] and Monzón et al. [29], and ensuring safety during the transfer (safety while waiting for the vehicle and when changing the means of transport), according to the results of the City-HUB project, Heddebaut [47]. The transfer conditions related to the differences in the levels necessary to overcome during the transfer, as well as the protection against unfavorable weather conditions, are indicated in the research by Żmuda-Trzebiatowski et al. [48].

With regard to the method used in the research, it should be mentioned that the problem of assessing interchanges in Poland was addressed by Olszewski P. et al. [31], proposing the AMPTI methodology, which is based on 14 quantitative indicators (currently eight indicators are recommended) and can be used to assess both existing and planned interchanges. The methodology presented above was used to evaluate 10 interchanges of public transport in Warsaw [32]. For each interchange, 14 rating indicators were derived from the interchanges audits, measurements, and surveys and identified interchange weaknesses. Another example of the application of the AMPTI method is the assessment of three interchange nodes in Cracow presented by Bryniarka Z., Czekała K. [49]; in this study, the interchange nodes were assessed using the AMPTI method using eight assessment indicators.

As a result, weaknesses of individual interchanges in relation to the considered assessment indicators were indicated. However, looking globally at this type of assessment, having the values of eight indicators for each of the interchanges, it is difficult to clearly assess which interchange is the most travel-friendly. In such cases, each indicator is analyzed separately for the interchange. For the assessment of five interchange nodes in Cracow, the authors of this study proposed a combination of two approaches so as to ultimately obtain an unambiguous global assessment for interchange, meaning an assessment that would take into account all indicators at the same time. Therefore, in addition to using the eight indicators proposed under the AMPTI method, the multicriteria method of ranking variants was also used the AHP method. As a result of the computational experiments, the final ordering of the analyzed transfer interchanges was obtained from the best to the worst in relation to the obtained global score, taking into account the considered assessment criteria. Thanks to this approach, it is easy to indicate which interchange is the most trip-friendly; additionally, on the basis of the calculated value of the utility function of the variants in relation to each criterion, it is possible to indicate weaknesses of a given interchange and suggest which criterion should be improved in order to make the interchange more user-friendly. A similar approach was used by Solecka K., Nosal Hoy K. [6] where two approaches, the AMPTI method and the multi-criteria 
decision aid method, were also combined to assess interchange nodes. However, in this case, one of the simplest methods was used: the compensation-conjunction method [50]. Based on the literature review, it can be concluded that there are currently few studies dealing with the issue of assessment of interchange nodes with the use of multi-criteria decision support methods.

\section{Conclusions}

The aim of the analysis implemented in this study was to assess the interchanges in Cracow, Poland, with regard to a set of criteria and rank the variants from best to worst with regard to these criteria. The analyses show that Rondo Grzegórzeckie is the best variant. In terms of the acceptance criteria, it has the best core infrastructure and passenger information; it is most friendly to the handicapped and elderly; it is also characterized with the best legibility in the interchange. The second-ranked Rondo Mogilskie is the best variant in terms of safety in motion in view of a large number of underground passages and no collision with car traffic, and it has the best additional equipment. The variant of the Krowodrza Gorka interchange was ranked at the end. The interchange has no roofs on most of the platforms, and it is not friendly to the handicapped. The interchange also scored the lowest in terms of safety in motion due to the absence of traffic lights at pedestrian crossings. The interchange is the best in terms of walking distances. A multi-criteria assessment of interchanges shows which interchanges are more friendly to passengers than others. The analysis indicates a direction of modifications; elements may be identified to be improved so that such interchange may become more friendly to passengers. Improved functioning of interchanges may increase the number of passengers on public transport and will cause passengers to be more willing to use interchanges-which means that they will make transfers in their trips.

During the implementation of research related to the assessment of interchange nodes, we encounter a number of problems, in particular related to the proper definition of evaluation indicators, parameterization of indicators, or the availability of data for determining indicators. In order to determine the assessment indicators, it is usually necessary to conduct a detailed interchange audit, measurement or survey. The first two tools do not cause major problems but are very time-consuming, which translates into the cost of work, while survey research requires contact with other people. Currently, direct contact is very difficult; people are reluctant to engage in discussions while on the interchange. On the one hand, they feel threatened, and on the other hand, they are afraid that they will miss their means of transport. Surveys can also be conducted via websites, but also, in this case, access to some social groups is difficult. Willingness to perform an analysis, e.g., from the point of view of the elderly, through websites, is practically impossible; the elderly often do not use computers and the Internet fluently or have difficult access to them. The return in this case of online questionnaires would be negligible. Surveys are also necessary in the case of using methods of multi-criteria decision support, which require determining the weighting of the criteria or, for example, obtaining comparisons between criteria or variants according to criteria. Therefore, in the case of more advanced research, it is proposed to use the experience and knowledge of experts (study in the article was based on the knowledge of transport experts).

In the case of applying multi-criteria decision aid methods, one of the main limitations in the use of more advanced methods is the availability of software, which is mostly paid and sometimes also difficult to access. In this study, the AHP method was used, which is characterized by a relatively simple calculation algorithm, which does not require the use of advanced computer programs.

In order to deepen the analyses related to the assessment of interchange nodes, it is proposed to carry out a sensitivity analysis in further studies, which will allow to determine the impact of the change in the importance of individual elements on the obtained results (final ranking). The starting point for such analysis may be a change in the values of individual evaluation criteria and observation of how the final rankings change. To perform 
this type of analysis, it is suggested to use Expert Choice software, which can greatly facilitate the work related to the calculations as well as gives the possibility of a graphical presentation of the results. Moreover, in order to deepen the analysis, it is suggested to evaluate the interchange nodes from various points of view, e.g., from the point of view of people with reduced mobility, as well as from the point of view of the city authorities. The research may also extend the set of criteria by, for example, economic criteria. The results of the assessment can be used to prepare recovery and modernization plans for the assessed interchanges, where the greatest problems have been identified; they are also a guideline for planning and designing new interchanges. Investments related to the design of interchange nodes and, furthermore, integrated interchange nodes are a complex and long-term process. In Poland, in the absence of legible legal legislation, they require a goodwill to cooperate from various parties, for example, on the part of railways, communes, starosties, provinces, and carriers. Investments are often implemented "quickly" without exchanging experiences and without proper recognition of the needs of future users, resulting in higher operating costs and underdeveloped design solutions. In Poland, local governments seem to be well prepared to organize interchanges nodes. Another problem is the negligible number of good Polish examples. That is why the right attitude of designers and the search for appropriate foreign solutions is very important. Integrated interchange nodes are being built in Poland, but often the solutions adopted do not work in practice, and the impressive objects are not effective at the same time. The most common problem is the lack of appropriate experience of designers and decision makers. It is recommended that at the national level, in particular, focus on the needs of users in legal acts, including those related to the construction of elements of transport infrastructure and interchanges. A valuable solution would be to create instructions and guides on how to properly plan passenger-friendly interchange nodes. In addition, it is suggested that when assessing the application for funding for junction construction projects, greater attention should be paid to the planning of interchange nodes adapted to the needs of all users, paying particular attention to the criteria of basic infrastructure, information, and personal and traffic safety. Local governments should pay particular attention to ensuring a high level of basic infrastructure, focusing on improving the infrastructure around platforms, walkways, and stairs and paying special attention to the surface, width, roofing, as well as the presence of obstacles within the platforms, pavements, and stairs in the interchanges. It is necessary to ensure access to the infrastructure of the integration interchange surroundings (parking lots, bicycle paths). There are many potential threats in the interchange areas, both for travelers and people working in such facilities. Therefore, it is recommended to pay special attention to the elements related to the lighting of sidewalks, platforms, bus shelters, proper lighting of information elements, so that travelers have no problem with reading them after dusk; monitoring and the possibility of contact with uniformed services should be provided-the presence of such services on the platforms. At pedestrian crossings within junctions, it is recommended to use additional elements that improve safety, such as reflective points installed in the road, appropriately selected times between green in controlling traffic lights, and acoustic announcements informing about the color of the displayed signal for pedestrians. It is recommended that local governments and carriers strive to provide comprehensive, integrated information, including information tailored to particularly sensitive groups. Information on the departures of subsequent buses, trams, and trains (in chronological order), traffic delays, and breakdowns should be provided; thus, the Passenger Information System would fulfill its real role by integrating various carriers, remembering to ensure the legibility of information, the height at which the information is located, ease of reception, voice information, and legible timetables. Moreover, one should strive to ensure the integrated frequency of timetables of individual means of transport.

It is widely recognized that passenger-friendly interchanges play a significant role in increasing the attractiveness and competitiveness of public transport and are often the showcase of the city transport system. 
Author Contributions: Conceptualization, K.S. and Ł.D.; methodology, K.S., Ł.D., I.T. and Y.L.; software, K.S. and Ł.D.; validation, I.T. and Y.L.; formal analysis, K.S., Ł.D., I.T. and Y.L.; investigation, K.S., Ł.D., I.T. and Y.L.; data curation, K.S. and Ł.D.; writing-review and editing, K.S., Ł.D., I.T. and Y.L. All authors have read and agreed to the published version of the manuscript.

Funding: This research received no external funding.

Institutional Review Board Statement: This study did not involve humans or animals.

Informed Consent Statement: Not applicable.

Data Availability Statement: Not applicable.

Conflicts of Interest: The authors declare no conflict of interest.

\section{References}

1. Hernandez, S.; Monzon, A. Key factors for defining an efficient urban transport interchange: Users' perceptions. Cities 2016, 50, 158-167. [CrossRef]

2. Oostendorp, R.; Gebhardt, L. Combining means of transport as a users' strategy to optimize traveling in an urban context: Empirical results on intermodal travel behavior from a survey in Berlin. J. Transp. Geogr. 2018, 71, 72-83. [CrossRef]

3. Monzón, A.; Hernández, S.; Di Ciommo, F. Efficient Urban Interchanges: The City-HUB Model. Transp. Res. Procedia 2016, 14, 1124-1133. [CrossRef]

4. Sun, G.; Lau, C.Y. Go-along with older people to public transport in high-density cities: Understanding the concerns and walking barriers through their lens. J. Transp. Health 2021, 21, 101072. [CrossRef]

5. Low, W.; Cao, M.; De Vos, J.; Hickman, R. The journey experience of visually impaired people on public transport in London. Transp. Policy 2020, 97, 137-148. [CrossRef]

6. Solecka, K.; Nosal-Hoy, K.; Deryło, A. Assessment of transport interchanges for the needs of people with reduced mobility. Travel Behav. Soc. 2020, 21, 48-56. [CrossRef]

7. Yen Barbara, T.H.; Mulley, C.; Tseng, W.C.; Chiou, Y.C. Assessing interchange effects in public transport: A case study of South East Queensland, Australia. Case Stud. Transp. Policy 2018, 6, 364-375. [CrossRef]

8. Taran, I.; Litvin, V. Determination of rational parameters for urban bus route with combined operating mode. Transp. Probl. 2018, 13, 157-171. [CrossRef]

9. Naumov, V.; Zhamanbayev, B.; Agabekova, D.; Zhanbirov, Z.; Taran, I. Fuzzy-logic approach to estimate the passengers' preference when choosing a bus line within the public transport system. Commun. Sci. Lett. Univ. Zilina 2021, 23, A150-A157. [CrossRef]

10. Hernández, S.; Monzón, A.; de Oña, R. Urban transport interchanges: A methodology for evaluating perceived quality. Transp. Res. Part A Policy Pract. 2016, 84, 31-43. [CrossRef]

11. Act of 16 December 2010 on Public Collective Transport, Journal of Laws of 2011, No.5, Item 13, as Amended. Available online: http:/ / isap.sejm.gov.pl/isap.nsf/DocDetails.xsp?id=wdu20110050013 (accessed on 2 September 2021).

12. Mills, G.; White, P.R. Evaluating the long-term impacts of bus-based park and ride. Res. Transp. Econ. 2018, 69, 536-543. [CrossRef]

13. Katoshevski-Cavari, R.; Bak, N.; Shiftan, Y. Would free park-and-ride with a free shuttle service attract car drivers? Case Stud. Transp. Policy 2018, 6, 206-213. [CrossRef]

14. Bryniarska, Z.; Żakowska, L. Multi-criteria evaluation of public transport interchanges. Transp. Res. Procedia 2017, 24, 25-32. [CrossRef]

15. Lunke, E.B. Commuters' satisfaction with public transport. J. Transp. Health 2020, 16, 100842. [CrossRef]

16. Chauhan, V.; Gupta, A.; Parida, M. Demystifying service quality of Multimodal Transportation Hub (MMTH) through measuring users' satisfaction of public transport. Transp. Policy 2021, 102, 47-60. [CrossRef]

17. Lois, D.; Monzón, A.; Hernández, S. Analysis of satisfaction factors at urban transport interchanges: Measuring travellers' attitudes to information, security and waiting. Transp. Policy 2018, 67, 49-56. [CrossRef]

18. Mulley, C.; Nelson, J.D. Public Transport Network Planning. Int. Encycl. Transp. 2021, 388-394. Available online: https: //www.sciencedirect.com/science/article/pii/B978008102671710781X?via\%3Dihub (accessed on 2 September 2021). [CrossRef]

19. Gkiotsalitis, K. A model for modifying the public transport service patterns to account for the imposed COVID-19 capacity. Transp. Res. Interdiscip. Perspect. 2021, 9, 100336. [CrossRef]

20. Shesterov, E.; Mikhailov, A. Method of evaluating transit hubs in Saint Petersburg. Transp. Res. Procedia 2020, 50, 654-661. [CrossRef]

21. Espino, R.; de Dios Ortúzar, J.; Rizzi, L.I. The Value of Security, Access Time, Waiting Time, and Transfers in Public Transport. Int. Encycl. Transp. 2021, 122-126. Available online: https://www.sciencedirect.com/science/article/pii/B978008102671710020X? via\%3Dihub (accessed on 2 September 2021). [CrossRef]

22. Khattak, A.; Hussain, A. Hybrid DES-PSO framework for the design of commuters' circulation space at multimodal transport interchange. Math. Comput. Simul. 2021, 180, 205-229. [CrossRef]

23. Lee, E.; Zaman Patwary, A.U.; Huang, W.; Lo, H.K. Transit interchange discount optimization using an agent-based simulation model. Procedia Comput. Sci. 2020, 170, 702-707. [CrossRef] 
24. Narayan, J.; Cats, O.; Van Oort, N.; Hoogendoorn, S. Integrated route choice and assignment model for fixed and flexible public transport systems. Transp. Res. Part C Emerg. Technol. 2020, 115, 102631. [CrossRef]

25. Naumov, V. Genetic-based algorithm of the public transport lines synchronization in a transfer node. Transp. Res. Procedia 2020, 47, 315-322. [CrossRef]

26. Carpio-Pinedo, J.; Martínez-Conde, J.A.; Daudén, F.L. Mobility and Urban Planning Integration at City-regional Level in the Design of Urban Transport Interchanges (EC FP7 NODES Project-Task 3.2.1.). Procedia Soc. Behav. Sci. 2014, 160, $224-233$. [CrossRef]

27. Lucietti, L.; Hoogendoorn, C.; Cré, I. New Tools and Strategies for Design and Operation of Urban Transport Interchanges. Transp. Res. Procedia 2016, 14, 1240-1249. [CrossRef]

28. Daudén, F.L.; Carpio-Pinedo, J.; García-Pastor, A. Transport Interchange and Local Urban Environment Integration. Procedia Soc. Behav. Sci. 2014, 160, 215-223. [CrossRef]

29. Monzón, A.; Alonso, A.; López-Lambas, M. Joint analysis of intermodal long distance-last mile trips using urban interchanges in EU cities. Transp. Res. Procedia 2017, 27, 1074-1079. [CrossRef]

30. Yatskiv, I.; Savrasovs, M.; Kabashkin, I.; Nathanail, E.G.; Adamos, G.; Mitropoulos, L.K. Knowledge Sharing Strategy as a Key Element of the H2020 Programme: Enhancing Excellence and Innovation Capacity in Sustainable Transport Interchanges (Alliance) Project. Procedia Eng. 2017, 187, 458-464. [CrossRef]

31. Krukowska, H.; Krukowski, P.; Olszewski, P. Metodyka Oceny Wskaźnikowej Węzłów Przesiadkowych Transportu Publicznego [Indicator Assessment of Public Transport Interchanges]. Urban Reg. Transp. 2014, 6, 4-6.

32. Transplan Konsulting, Wykorzystanie Metody Wskaźnikowej i Ankietowej do Oceny Wybranych Węzłów Przesiadkowych w Warszawie [Use of the Indicator Method and Questionnaires to Assess Selected Interchanges in Warsaw]. Available online: http: //siskom.waw.pl/komunikacja/wezly/Transplan/Wykorzystanie_metody_wskaznikowej_i_ankietowej_do_oceny_WP.pdf (accessed on 10 August 2020).

33. Saaty, T.L. The Analytic Hierarchy Process: Planning, Priority Setting, Resources Allocation; Mcgraw-Hill: New York, NY, USA, 1980.

34. Roy, B. Multiple Criteria Decision Aid; Wydawnictwo Naukowo-Techniczne: Warsaw, Poland, 1990.

35. Vincke, P. Multicriteria Decision-Aid; John Wiley\&Sons: Chichester, UK, 1992; 174p.

36. Wolnowska, A.; Konicki, W. Multi-criterial analysis of oversize cargo transport through the city, using the AHP method. Transp. Res. Procedia 2019, 39, 614-623. [CrossRef]

37. Broniewicz, E.; Ogrodnik, K. Multi-criteria analysis of transport infrastructure projects. Transp. Res. Part D Transp. Environ. 2020, 83, 102351. [CrossRef]

38. Żak, J.; Kruszyński, M. Application of AHP and ELECTRE III/IV Methods to Multiple Level, Multiple Criteria Evaluation of Urban Transportation Projects. Transp. Res. Procedia 2015, 10, 820-830. [CrossRef]

39. Nosal, K.; Katarzyna Solecka, K. Application of AHP Method for Multi-criteria Evaluation of Variants of the Integration of Urban Public Transport. Transp. Res. Procedia 2014, 3, 269-278. [CrossRef]

40. Szatmári, M. Proposal AHP method for Increasing the Security Level in the Railway Station. Transp. Res. Procedia 2021, 55, 1681-1688. [CrossRef]

41. Fernandez, J.J.; Maria Cecilia Paringit, M.C.; Salvador, J.R.; Paolo Ian Lucero, P.I.; Joenel, G.; Galupino, J.G. Driver's Road Accident Factor Prioritization using AHP in Relation to Mastery of Traffic Signs in the City of Manila. Transp. Res. Procedia 2021, 48, 1316-1324. [CrossRef]

42. Ignaccolo, M.; Inturri, G.; García-Melón, M.; Giuffrida, N.; Le Pira, M.; Torrisi, V. Combining Analytic Hierarchy Process (AHP) with role-playing games for stakeholder engagement in complex transport decisions. Transp. Res. Procedia 2017, $27,500-507$. [CrossRef]

43. Basbas, C.M.; Makridakis, A. Review of the contribution of multi-criteria analysis to the evaluation process of transportation projects. Int. J. Sustain. Dev. Plan. 2007, 2, 387-407. [CrossRef]

44. Boujelbene, Y.; Derbel, A. The Performance Analysis of Public Transport Operators in Tunisia Using AHP Method. Procedia Comput. Sci. 2015, 73, 498-508. [CrossRef]

45. Huang, I.B.; Keisler, J.; Linkov, I. Multi-criteria decision analysis in environmental sciences: Ten years of applications and trends. Sci. Total Environ. 2011, 409, 3578-3594. [CrossRef]

46. Starzyńska, B.; Kujawińska, A.; Grabowska, M.; Diakun, J.; Więcek-Janka, E.; Schnieder, L.; Schlueter, N.; Nicklas, J.-P. Requirements elicitation of passengers with reduced mobility for the design of high quality, accessible and inclusive public transport services. Manag. Prod. Eng. Rev. 2015, 6, 70-76. [CrossRef]

47. Heddebaut, O. Creating sustainable and efficient transport interchanges: Some findings of the city-HUB project. Adv. Civ. Eng. Technol. 2018, 1, 3. [CrossRef]

48. Zmuda-Trzebiatowski, P.; Bienczak, M.; Kiciński, M.; Fierek, S. Wielokryterialna ocena wariantów przebudowy skrzyżowania z ruchem okrężnym na przykładzie modernizacji Ronda Rataje w Poznaniu [Multiple criteria evaluation of different redesign variants of the roundabout Rataje in Poznan City]. TTS Tech. Transp. Szyn. 2012, 9, 4585-4594.

49. Czekała, K.; Bryniarska, Z. Ocena wskaźnikowa wybranych węzłów przesiadkowych publicznego transportu zbiorowego w Krakowie [The empty method for assessment of selected interchanges in Krakow's public transport]. Transp. Miejski i Reg. 2017, $6,5-10$.

50. Rudnicki, A. Quality of Urban Transportation; SITK: Kraków, Poland, 1999; pp. 199-202. 